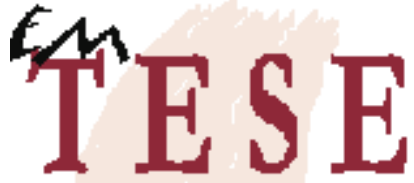

Revista Eletrônica dos Pós-Graduandos em Sociologia Política da UFSC

Vol. 6 - n. 3 janeiro-julho/2009

ISSN 1806-5023

\section{Capitalismo contemporâneo: Karl Marx e a crise financeira do século XXI}

Letícia Fiera*

Resumo: O presente artigo procura oferecer uma breve revisão de algumas das considerações de Karl Marx acerca da categoria dinheiro. A primeira consideração compreende o dinheiro como uma instituição social capaz de mediar as necessidades humanas. A segunda, trata da expansão e das potencialidades do crédito, ou seja, da capacidade do dinheiro em se transformar em mais dinheiro. Por fim, as implicações de uma crise financeira advindas da globalização.

Palavras-chaves: dinheiro, poder, mediação, globalização financeira, expansão do crédito, desregulamentação, crise

Abstract: This article seeks to provide a brief review of some of the considerations of Karl Marx about the money category. The first consideration comprises cash as a social institution capable of mediating human needs. The second is the expansion and the potentialities of credit, ie, the ability of money to turn into more money. Finally, the implications of a financial crisis resulting from globalization.

Key-Words: money, power, mediation, financial globalization, credit expansion, deregulation, crises.

O objetivo deste artigo é explorar a problemática do dinheiro através do pensamento clássico de Karl Marx. Nosso intuito é relembrar algumas das muitas observações que este autor fez acerca do dinheiro e tentar, com isso, compreender a dinâmica do capitalismo contemporâneo diante da crise financeira que assola o mundo neste início de século XXI.

\footnotetext{
* Mestre em lingüística e doutoranda no Programa de Pós-Graduação em Sociologia Política na Universidade Federal de Santa Catarina.
} 


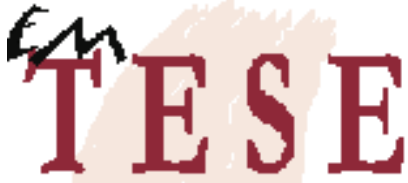

Revista Eletrônica dos Pós-Graduandos em Sociologia Política da UFSC

Vol. 6 - n. 3 janeiro-julho/2009

ISSN 1806-5023

Seria uma grande ousadia de nossa parte, tentar aqui, neste breve espaço, descrever a História das Idéias deste autor clássico. Consideramos, porém, que a categoria "dinheiro" é central para o debate contemporâneo, pois como observado pelo autor acima citado, o dinheiro surge, aparentemente, como meio neutro de intercâmbio, acumulação de valor e como poder de mediação da satisfação das necessidades humanas, individuais e sociais. Assim, o dinheiro está presente em todas as relações sociais, sejam elas de caráter impessoais e neutras, por exemplo, compra e venda de objetos transformados em mercadoria (lógica do mercado), nas relações de trabalho (patrão/empregado) ou mesmo nas relações familiares. No entanto, o dinheiro circula na sociedade sob várias formas. Podemos encontrá-lo nas moedas correntes de cada país, nos tickets alimentares ou refeições, cheques, cartões de crédito e em outras formas de notação e contratos ${ }^{1}$.

É nossa preocupação não cometermos nenhum tipo de anacronismo, como sugere Quentin Skinner (2003), com os textos clássicos em relação ao mundo contemporâneo, atribuindo a eles significados que não estejam relacionados ao seu tempo. Porém, retornar a este autor clássico nos permite orientar e identificar de que forma a categoria dinheiro era entendida, em sua época e contexto, e qual a contribuição para a compreensão da sociedade contemporânea e de suas relações econômico/sociais.

Estas observações nos encaminham de pronto a uma questão preliminar que gostaríamos de explorar preliminarmente: qual a validade de recorrermos a Karl Marx uma vez que ele procurou compreender a modernidade a partir do contexto real no qual estava inserido? A reflexão de Alexander (1999) quanto à natureza do trabalho dos autores que se tornam clássicos em suas áreas de conhecimento nos auxilia nessa resposta:

um clássico é o resultado do primitivo esforço da exploração humana que goza de status privilegiado em face da exploração contemporânea no mesmo campo. O conceito de status privilegiado significa que os

\footnotetext{
${ }^{1}$ Nos referimos aqui à economia solidária.
} 


\section{T⿱幺 ESE}

Revista Eletrônica dos Pós-Graduandos em Sociologia Política da UFSC

Vol. 6 - n. 3 janeiro-julho/2009

ISSN 1806-5023

modernos cultores da disciplina em questão acreditam poder aprender tanto com o estudo dessa obra antiga quanto com o estudo da obra de seus contemporâneos (Alexander, 1999: 24).

Portanto, muitas das reflexões de Karl Marx que serão exploradas aqui se encontram, embora formuladas no século XIX, em sintonia com a realidade dos dias atuais, conferindo dessa forma uma vitalidade teórica singular para a compreensão do capitalismo em suas manifestações contemporâneas. O método histórico, que nos leva a apontar tanto às permanências quanto às mudanças como forma de análise de um processo social, nos servirá de guia para a elaboração das reflexões a respeito das idéias do pensador clássico em tela e da realidade do século XXI.

\section{As contribuições de Karl Marx acerca do dinheiro}

Considerando as assertivas ontológicas do dinheiro como um objeto de poder capaz de mediar as necessidades humanas na Modernidade, iremos nos apoiar nas reflexões de Karl Marx, principalmente no sexto capítulo do Manuscritos EconômicoFilosóficos. Neste capítulo, Marx diz que o dinheiro se constitui como mediador das necessidades humanas, é ele que tem a capacidade de satisfazer tais necessidades no qual os sentimentos e as paixões individuais não são vistas como características antropológicas, mas afirmações ontológicas do ser.

O dinheiro para Marx é, portanto, o objeto que possibilita a compra e a apropriação dos objetos e, principalmente, satisfazer os desejos das necessidades humanas. Para Marx, o dinheiro foi institucionalizado como uma força social pelo homem da sociedade moderna. Ele se questiona se a força social do dinheiro não seria, enfim, "o laço de todos os laços", uma vez que ela possibilita o vínculo do indivíduo à vida humana e através do dinheiro procura torná-lo um meio de separação e união e, ao 


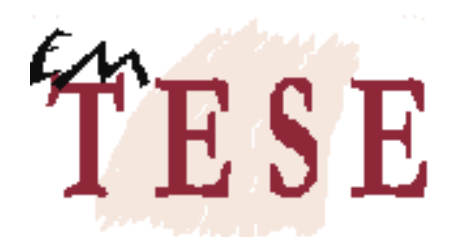
Revista Eletrônica dos Pós-Graduandos em Sociologia Política da UFSC
Vol. 6 - n. 3 janeiro-julho/2009
ISSN 1806-5023

mesmo tempo, une o indivíduo à sociedade, ou seja, estabelece a união do indivíduo à natureza e ao próprio homem. Diz Marx (2001):

Mas o homem não é exclusivamente um ser natural; é um ser natural humano; ou melhor, um ser para si mesmo, por conseqüência, um ser genérico, e como tal tem de legitimar-se e expressar-se tanto no ser como no pensamento. Deste modo, nem os objetos humanos são objetos naturais, como eles se apresentam diretamente, nem o sentido humano, tal como é imediata e diretamente dado, constitui a sensibilidade humana, a objetividade humana, nem a natureza objetiva, nem a natureza subjetiva se apresentam prontamente ao ser humano numa forma adequada. E assim como tudo o que é natural deve ter a sua origem, também o homem tem o seu processo de gênese, a história, que, no entanto para ele constitui um processo consciente e que assim, como ato de origem com consciência, se transcende a si próprio. A história é a verdadeira história natural do homem [...] (MARX, 2001: 169)

As verdadeiras necessidades do homem se transformam, portanto, na necessidade do dinheiro e nas necessidades quantitativas e subjetivas que ele mesmo pode produzir. Desta forma, para Marx (2001),

cada homem especula sobre a maneira como criar no outro uma nova necessidade para forçá-lo a novo sacrifício, o colocar em nova dependência, para atraí-lo a uma nova espécie de prazer e, dessa forma, à destruição. Cada qual procura impor sobre os outros um poder estranho, de modo a encontrar assim a satisfação da própria necessidade egoísta. Com a multidão dos objetos, cresce de forma igual o império das entidades estranhas a que o homem se encontra sujeito. Todo o produto novo constitui uma nova potencialidade de mútuo engano e roubo. $\mathrm{O}$ homem torna-se cada vez mais pobre como homem, necessita cada vez mais de dinheiro, para poder tomar posse do ser hostil. O poder do seu dinheiro enfraquece em dimensão oposta à massa da produção, ou seja, a sua necessidade aumenta na medida em que cresce o poder do dinheiro. A necessidade do dinheiro constitui, assim, a verdadeira necessidade criada pelo moderno sistema econômico e é a única necessidade que ele produz. A quantidade do dinheiro torna-se progressivamente a sua única propriedade importante; assim como ele reduz toda a entidade a uma abstração, assim se reduz a si no seu próprio desenvolvimento a uma 


\section{T⿱幺 ESE}

Revista Eletrônica dos Pós-Graduandos em Sociologia Política da UFSC

Vol. 6 - n. 3 janeiro-julho/2009

ISSN 1806-5023

entidade quantitativa. $\mathrm{O}$ excesso e a não-moderação tornam-se a sua verdadeira medida. É o que se manifesta no plano subjetivo, em parte porque a expansão dos produtos e das necessidades se transforma em subserviência engenhosa e sempre baseada nos apetites inumanos, corrompidos, antinaturais e fantasiosos (MARX, 2001:149)

No entanto, para Marx, o dinheiro não é um mero véu que oculta às trocas entre produtos sem alterar em nada a substância dessas trocas. De acordo com Marx (2001) o verdadeiro poder do dinheiro se concentra no fato dele se apresentar como um "inversor universal", ou seja, transformar, na sociabilidade humana, valor de uso em valor de troca, bem ou serviço em mercadoria. Assim, o dinheiro teria a capacidade de inverter e mesmo dar qualidades a quem o possui, sendo a maior dessas qualidades a potencialidade de possuir o que lhe aprouver, subjugando àqueles que the desejam despojar de sua posse, sem que o poderoso esteja imune aos problemas que a possibilidade subjetiva de perda do dinheiro traz. Ou seja, a vida social torna-se uma luta entre àqueles que não possuem o dinheiro e, portanto, o desejam, e àqueles que o possuem, mas que temem perdê-lo, com todos "presos" em sua sociabilidade ao poder intrínseco que a posse ou a falta do dinheiro produz:

a inversão geral das individualidades, transformando-as nos seus opostos e associando qualidades contraditórias com as suas qualidades (...) o mundo invertido, a confusão e a transposição de todas as qualidades naturais e humanas (...) força os contrários a abraçar-se (MARX, 2001: 170-171)

Prossegue Marx, (2001):

Cada um se apresenta ao outro como possuidor de dinheiro, como o dinheiro mesmo, contanto que se considere o processo da troca. Isto porque a indiferença e a equivalência estão na forma da coisa. A diversidade natural particular que comportava a mercadoria se apagou, e é continuamente apagada pela circulação (MARX, 2001: 186). 


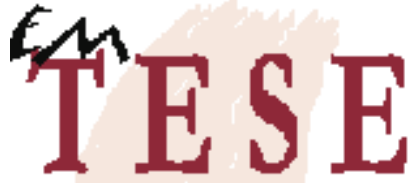

Revista Eletrônica dos Pós-Graduandos em Sociologia Política da UFSC

Vol. 6 - n. 3 janeiro-julho/2009

ISSN 1806-5023

Assim, podemos considerar que o dinheiro aparece como valor de troca e valor de uso, e que nos dizeres de Marx ele seria a "proxeneta entre a necessidade e objeto, entre vida e os meios do homem", elevando ao máximo a "confusão de todas as qualidades humanas e naturais". O dinheiro, portanto, se torna o caráter auto-alienante da humanidade. "O dinheiro converte as representações pensadas para o modo de existência sensível", concreto, efetivo. É ele, o "mediador final de todas as mediações alienadas": o fetichismo do dinheiro. O dinheiro é dessa forma o "proxeneta universal dos povos e dos homens".

Para Marx, a sociedade toma o dinheiro e o lucro como um dos principais elementos responsáveis pela existência humana. Ela revela-se dividida entre os proprietários dos meios de produção - terras, indústrias, dinheiro - e os que vendem suas forças de trabalho - trabalhadores/empregados.

O dinheiro é, portanto, para Marx, o problema da modernidade por excelência. Ele é a essência da vida social capaz de ordenar, unir e vivificar todas as manifestações da vida e da produção dos indivíduos. Por este motivo, Marx, no Manifesto Comunista, afirma que, na modernidade, diferentemente do que era na Antigüidade clássica, por exemplo, "o dinheiro é também imediatamente por sua vez o ser real da comunidade" (Marx, 2001, p.164).

É o dinheiro que simboliza o poder de tudo comprar e consequentemente de tudo realizar e, simbolizando tal poder (que não tem origem nas forças essenciais do homem, mas que o submete), a ele é transferido toda e qualquer possibilidade de realização do indivíduo.

Em uma abordagem incompleta, mas importante, Marx, no livro III de O Capital, trata das potencialidades do crédito e da expansão da forma D-D' como aquela manifestação mais fetichizada do capital. Esse circuito restrito do capital, ou seja, a possibilidade de transformação direta de dinheiro em mais dinheiro por via da aquisição de títulos ou do crédito (avanços de capital sobre uma produção futura) apareceria ao 


\section{T⿱幺 ESE}

Revista Eletrônica dos Pós-Graduandos em Sociologia Política da UFSC

Vol. 6 - n. 3 janeiro-julho/2009

ISSN 1806-5023

"investidor/aplicador" tão natural e regular "quanto da pereira nascem pêras" (Marx, livro III, cap, XXIV). Natural, pois ele não se questiona quanto à origem desse rendimento. Regular, pois, nesse caso, as "pereiras" dão frutos em prazos prédeterminados, independentemente das condições subjacentes.

Ou seja, o fetichismo do capital-dinheiro esconde que esses frutos são, em realidade, necessariamente parte da mais-valia futura a ser apropriada sob a forma de impostos (títulos públicos) ou lucros (títulos privados). Daí a oposição entre o capital que cumpre todo o circuito produtivo D-M-D' e àquele capital dito "fictício" - uma vez que a produção que o remunerará ainda não foi realizada, que se reproduz a partir do circuito mais restrito D-D'. Na medida em que existem momentos de euforia financeira, existe uma possibilidade de frutificação ilimitada dessa forma de capital, até a emergência de uma crise que o destrua. Ou seja, a embriaguez social causada pela potencialidade do dinheiro produzir mais dinheiro durante o auge de um ciclo especulativo/financeiro esconde a origem dessa multiplicação, ao mesmo tempo em que porta em si a inevitabilidade de sua destruição, o que ocorre regularmente nos episódios de crises financeiras. Essa análise de Marx mostrar-se-á de fundamental importância para a compreensão do capitalismo contemporâneo tanto por aquilo que este a nega quanto pelo que este a valida.

\section{A globalização financeira}

A atual fase do capitalismo conhecida como globalização nasce da combinação entre as inovações tecnológicas advindas da indústria eletrônica e consubstanciada na popularização e difusão da informática com a desregulamentação dos mercados em suas três esferas (comercial, investimentos e financeira) a partir do final dos anos 1970. Têmse, portanto, duas determinações causais, uma de origem técnica e outra de origem política que agem simultaneamente, embora essa segunda ordem de fatores tenda a ser 


\section{T⿱⺈巴E SE}

Revista Eletrônica dos Pós-Graduandos em Sociologia Política da UFSC

Vol. 6 - n. 3 janeiro-julho/2009

ISSN 1806-5023

subestimada por um discurso ideológico que sublinha a natureza "moderna" e "irreversível" das transformações ocorridas nos últimos 25 anos (Chesnais, 2004).

Hoje, há um consenso ideológico, segundo Michalet (2003), que se funda na convicção de que as leis da ciência econômica são universais, ou seja, elas são aplicáveis em todas as situações, sem distinção de espaço geográfico. É nessa lógica sem território e sem espaço que o capital circula. Segundo Duménil (2005) ${ }^{2}$ :

"Se existe uma ideologia neoliberal, o neoliberalismo é muito mais do que isso, ou seja, é uma fase do capitalismo, na qual as características de exploração desse modo de produção, inclusive em sua dimensão imperialista, encontraram uma nova radicalidade: disciplina do trabalho e de sua gestão em favor dos detentores dos capitais (credores e acionistas); livre circulação das mercadorias e dos capitais ${ }^{3}$, quer dizer, globalização do terreno de caça do capital internacional ${ }^{4}$,"

É a partir deste cenário que a desregulamentação do mercado financeiro se desenvolve. Uma vez que "todos os capitais são, pela sua natureza, financeiros e, portanto, suscetíveis de se valorizar na esfera das aplicações - em que dinheiro se troca por dinheiro diferente - tendo em vista as expectativas" (Paul Singer, 1997) ${ }^{5}$.

É importante remontarmos às origens dessa etapa do capitalismo. Essas podem ser encontradas na desvinculação do dólar ao ouro entre 1971 e 1973. Este fato liberou a quantidade da "moeda mundial" ${ }^{6 "}$ da restrição quantitativa que lhe impunha a sua

\footnotetext{
${ }^{2}$ Gerard Duménil A América Latina na mundialização neoliberal. Retirado da internet: http://www.jourdan.ens.fr/levy/dge2005a.doc fevereiro 2005

${ }^{3}$ Grifo nosso

${ }^{4}$ Grifo nosso

5 Paul Singer. Economia: Da crise financeira à crise econômica. Retirado da internet: http://www2.fpa.org.br/portal/modules/news/article.php? storyid=2485.

6 O dólar torna-se moeda mundial a partir do Acordo de Bretton Woods (1944), consubstanciando a ascensão dos Estados Unidos à condição de potência econômica hegemônica após sua vitória (em conjunto com a URSS) na Segunda Guerra Mundial. Por moeda mundial tem-se que o dólar cumpre mundialmente as três funções da moeda: intermediário nas trocas, unidade de conta e reserva de valor. Ou seja, o dólar é a moeda na qual a riqueza é utilizada para a aquisição de bens e de serviços, a riqueza é contada e a riqueza é guardada. A partir desse momento, o rico, de qualquer nacionalidade, é rico em dólares, e não em outra moeda, situação que permanece até nossos dias.
} 


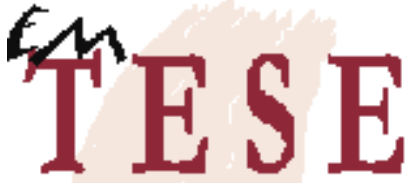

Revista Eletrônica dos Pós-Graduandos em Sociologia Política da UFSC

Vol. 6 - n. 3 janeiro-julho/2009

ISSN 1806-5023

relação fixa com o ouro. Essa mudança tornou o mundo econômico menos previsível e abriu oportunidades de ganhos especulativos que, após a década de 1930, estavam restritas por regulamentações quanto à conduta das empresas financeiras e da liberdade de movimentação de capitais financeiros ao redor do mundo.

A potencialidade dessas mudanças políticas foi exponencialmente amplificada pela revolução tecnológica trazida pela telemática, que é a combinação entre as telecomunicações e a informática. Esta permitiu o deslocamento de enormes massas de capital ao redor do globo, em um contexto de desregulamentação das atividades financeiras. Ou seja, a globalização financeira difere não apenas do período anterior (simplificadamente o período de Bretton Woods), em que as atividades financeiras se encontravam restritas, mas também de períodos de expansão financeira "livre" anteriores (período entre 1890-1920), pois nesse caso tínhamos uma expansão da esfera financeira limitada não apenas pelas regras do padrão-ouro como pela possibilidade técnica existente nos dias atuais ${ }^{7}$.

A conjunção desses fenômenos técnicos e políticos trouxeram significativas transformações na forma de acumulação e expansão do capital financeiro. De um lado, tivemos a emergência de novos atores que passaram a dominar a cena financeira. São eles os chamados investidores institucionais (fundos de pensão, fundos de investimentos, fundos hedge, bancos de investimento, seguradoras e, mais recentemente, os fundos de private equity e os fundos soberanos), os quais passaram a concentrar a poupança e as aplicações financeiras ao redor do planeta. De outro lado, a própria instabilidade inerente ao capitalismo financeiro desregulamentado trouxe a necessidade de criação de novos produtos financeiros como a securitização e os derivativos ${ }^{8}$.

\footnotetext{
7 Apesar disso, temos que aqui sublinhar o caráter político/tecnológico do processo em curso após a década de 1970, o qual não permite uma interpretação baseada no mero determinismo tecnológico como "causa' da expansão dos movimentos financeiros e da hegemonia desses movimentos sobre as demais formas de acumulação de capital em esfera mundial.

${ }^{8}$ A securitização refere-se ao processo de transformação de dívidas em títulos negociáveis permitindo que uma maior número de credores (geralmente os investidores institucionais) se exponha a um menor risco individual pois "carrega" apenas uma parte da dívida de uma
} 


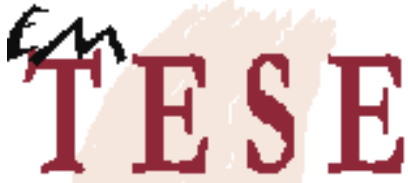

Revista Eletrônica dos Pós-Graduandos em Sociologia Política da UFSC

Vol. 6 - n. 3 janeiro-julho/2009

ISSN 1806-5023

Esses desenvolvimentos estão na base do que se convencionou chamar "finanças de mercado". O financiamento das empresas e dos governos se desloca dos bancos para a emissão de títulos negociáveis, em um negócio "auto-regulamentado". Para tanto, é crucial o papel das agências de notação (rating), as quais classificam os potenciais devedores conforme o seu risco de não pagamento, seguindo critérios que condicionam as estratégias e os objetivos das empresas e dos governos. O grande negócio da globalização financeira é a possibilidade de endividamento quase ilimitada, mas o acesso a esse financiamento em boas condições depende de bons níveis de rating. Ou seja, as agências têm um poder de vida ou morte sobre as empresas produtivas, pois uma piora nas condições de financiamento de uma empresa leva esta a ser presa fácil de suas concorrentes que obtém fundos em melhores condições, numa demonstração evidente da supremacia da finança sobre a produção nessa quadra histórica do capitalismo.

Não menos importante é a difusão da chamada "governança corporativa" a qual, a pretexto de proteger os proprietários das empresas (detentores do capital, em caso de uma companhia de capital aberto, de suas ações) dos seus diretores executivos (nas palavras de Marx, o "capitalista em função"). A tentativa de remediar essa oposição de interesses e de identificar a atuação dos diretores aos objetivos dos proprietários passa pela difusão de códigos de conduta que estimulam a ampla disseminação de informações da empresa aos proprietários (inclusive os acionistas ditos minoritários, dentre os quais se incluem os investidores institucionais) ao mesmo tempo em que mudam a forma de remuneração dos executivos, aumentando o peso das opções de compras de ações da empresa em seu salário (stock-options) ${ }^{9}$. O objetivo da empresa

empresa ou país, podendo negociá-la conforme sua estratégia de valorização do capital. Os derivativos são instrumentos complexos que, simplificadamente, permitem a operação do futuro no presente. Ou seja, dão ums eguro frente às flutuaçãoes abruptas às quais estão sujeitas as variáveis econômicas em um mundo instável. Os dois instrumentos permitem uma repartição dos riscos entre um maior numero de atores, ao mesmo tempo em que interligam mercados, potencialiando o risco de todo o sistema. A esse respeito ver Braga e Cintra (2004).

${ }^{9}$ Nesse contexto, os executivos percem em poder o que ganham em salários. Nas décadas de 1950 e 1960 a remuneraçãomédia de um executivo nas empresas de capital aberto dos dos 


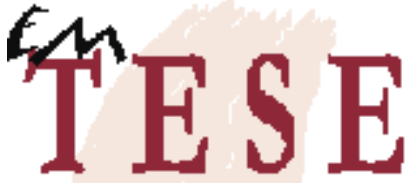

Revista Eletrônica dos Pós-Graduandos em Sociologia Política da UFSC

Vol. 6 - n. 3 janeiro-julho/2009

ISSN 1806-5023

"produtiva" capitalista passa a ser o de "maximizar o valor pra o acionista", ou, de forma mais simples, o aumento das cotações das ações da empresa ${ }^{10}$.

Essas transformações, as quais se consolidam nos anos 1980 e 1990, difundindose dos Estados Unidos à Europa e ao Japão e, posteriormente aos países que constituem o que o jargão financeiro em voga chama de "mercados emergentes", têm um enorme potencial de mudança social. A hegemonia do capital financeiro nesse período se traduz em sua lucratividade e em sua expansão exacerbada, superior às possibilidades de acumulação trazidas pelo comércio e pelo deslocamento internacional da produção (transnacionalização das empresas), embora estas dimensões sejam todas interdependentes. Michalet (2003) traz uma terceira característica, mais qualitativa, a qual nos parece mais interessante para esse trabalho. Diz ele, quanto à identificação da forma de capital dominante em um período histórico das relações capitalistas:

o terceiro critério é mais qualitativo e leva em consideração a racionalidade econômica dos operadores da dimensão dominante. Essa racionalidade tem a vocação de se difundir nas duas outras dimensões por meio de um fenômeno de imitação. A difusão se dá mediante a difusão do discurso da lógica dominante, apresentado por meio de consultores, professores, da imprensa e das mídias e de um círculo cada vez mais amplo de responsáveis econômicos do setor privado e do setor público que afirmam sua adesão à nova cultura (MICHALET, 2003: 65)

Ampliando um pouco e interpretando o que diz Michalet, temos que a racionalidade da finança e de seus operadores tende a se difundir enquanto parâmetro das relações que regem a vida em sociedade. Essa racionalidade cultua a velocidade, a rentabilidade e a segurança, em um mundo instável, onde as fortunas se fazem e se desfazem sem uma explicação "real" aparente, onde a "esperteza" aparece como uma qualidade que justifica um desempenho superior frente a um concorrente, uma vez que

Estados Unidos girava em torno de 50 vezes o salário médio dos trabalhadores. Essa relação passa a cerca de 200 vezes na década de 1990 no caso dos presidentes das empresas e chega a 350 vezes nos anos de 2002-2003. Reich (Supercapitalismo, 2008).

${ }^{10}$ A esse respeito ver Scherer (2003). 


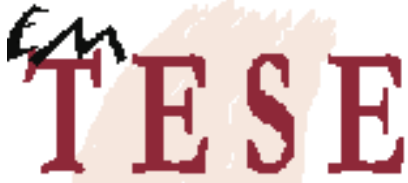

Revista Eletrônica dos Pós-Graduandos em Sociologia Política da UFSC

Vol. 6 - n. 3 janeiro-julho/2009

ISSN 1806-5023

os reais processos subjacentes à sucção da mais-valia em direção dos aplicadores financeiros encontram-se mascarada e nunca é explicitada ${ }^{11}$.

E aqui, Marx e suas considerações podem nos auxiliar de forma incontestável: quem pode negar que condutas anteriormente reprovadas socialmente são hoje aceitas pelos seus resultados em termos de acumulação de capital sem que se questionem os processos pelos quais esta acumulação foi obtida? E que até mesmo o "capital social" agora pode ser obtido e socialmente aceito sem a necessidade de uma justificativa em termos de trabalho ou de serviços relevantes, como bem comprova a cultura das chamadas "celebridades" hoje tão em voga no mundo todo e não apenas no Brasil ${ }^{12}$ ? A congruência dessas constatações com a natureza de um circuito do capital reduzido à forma D-D' é marcante. A reprodução dessas características enquanto parâmetro de conduta social faz com que os processos que eram antes exigidos enquanto etapas intermediárias para a validação/aceitação de uma conduta socialmente aceita possam ser ignoradas, tal qual a produção de mercadorias o é no circuito reduzido de Marx.

E, como previu Marx, esse processo é constantemente sujeito a crises. Aqui, a constatação é contraditória. Deve-se perguntar como tal processo de exacerbação do capital financeiro com tal descolamento da atividade produtiva pode subsistir há mais de 30 anos? A resposta para tal questão passa tanto pelo caráter eminentemente financeiro que toma o dinheiro apenas "fiduciário" - e, portanto, de expansão ilimitada enquanto nele se mantiver a confiança - a partir da década de 1970 quanto pelo caráter "globalizado" dessa atividade eminentemente especulativa. Cada circuito financeiro que se incorpora aos processos de acumulação globais coloca "água no moinho da finança" e permitem que a roda continue girando.

\footnotetext{
11 Nota-se um descolamento entre o avanço da produtividade e o avanço dos salários nos Estados Unidos após a década de 1980 que nos dá boas pistas quanto à real origem dos ganhos financeiros e da sustentação desse modelo. A esse respeito ver Reich (2008).

12 Esse processo é levado ao paroxismo em programas do tipo Big Brother, no qual um desconhecido é escolhido pelo público como preferido e ídolo sem que nada faça de socialmente relevante.
} 


\section{T⿱幺 ESE}

Revista Eletrônica dos Pós-Graduandos em Sociologia Política da UFSC

Vol. 6 - n. 3 janeiro-julho/2009

ISSN 1806-5023

Isso significa que Marx estava errado quanto à instabilidade intrínseca a um circuito reduzido D-D'? A profusão de crises financeiras após o advento da globalização financeira demonstra que não. Embora a resiliência desse sistema seja surpreendente, como anteriormente explicado, em realidade crises, de diversas naturezas e conseqüências emergiram nos Estados Unidos na década de 1980 e início da década de 1990, no Japão em 1991, no México em 1996, na Ásia em 1997, na Rússia e no Brasil em 1998, nos Estados Unidos no ano 2000, na Argentina em 2001, no Brasil em 2002 e novamente nos Estados Unidos em 2007. Certamente, essa lista não é exaustiva, e bem demonstra que a natureza dos sistemas financeiros desregulados é propensa à crises que se repetem.

Cabe aqui uma ressalva quanto à natureza da atual crise financeira norteamericana, que vem sendo considerada "a maior crise desde a grande Depressão" (Roubini, Nouriel - www.rgemonitor.com). Sua gravidade é imensa e sua duração incerta. A exacerbação de novos produtos financeiros (ou seja, do circuito D-D') parece ter chegado ao paroxismo no período 2002-2007, com a criação de títulos securitizados cada vez mais complexos (títulos com base em títulos, com base em títulos, etc.), sobre os quais se transacionavam derivativos baseados em índices de títulos, todo comercializado em escala mundial. Pode parecer confuso, e é, mas, trata-se da fetichização mais completa das atividades produtivas (notadamente da construção de imóveis comerciais e residenciais nos Estados Unidos) escondidas atrás da venda de ativos que a elas correspondiam ao menos parcialmente ${ }^{13}$. Ou seja, Marx pode ter novamente a palavra final, uma vez que esse processo não poderia seguir indefinidamente, sendo inclusive a forma como se apresentou nos anos 2000, já uma amostra da retração da lucratividade no setor financeiro do país central, detentor do dinheiro mundial.

\section{Considerações finais}

${ }^{13}$ Ver a esse respeito Cintra e Scherer (2008). 


\section{T⿱幺 ESE}

Revista Eletrônica dos Pós-Graduandos em Sociologia Política da UFSC

Vol. 6 - n. 3 janeiro-julho/2009

ISSN 1806-5023

A forma como o sistema capitalista se apresenta parece ter uma influência crucial para o contorno da vida em sociedade. Isto não quer dizer que a economia prevaleça nesta relação, ao contrário, vimos com Karl Marx que as estruturas sociais ao sistema capitalista têm uma contribuição relevante na interpretação do movimento do capital na sociedade contemporânea.

Consideramos, portanto que é necessário pensar o capitalismo não como o fim da história, mas como uma etapa histórica da humanidade. O resgate das idéias de Karl Marx nos permite servir de amparo para um pensamento teórico sobre a atual fase do capitalismo, descobrir suas ações e as suas determinações societárias.

Assim, observamos com Marx que ele empreende uma crítica ao surgimento da sociedade industrial que estava em ebulição. Ele procurou salientar nas suas considerações a verdadeira essência do homem moderno. Este que parece procurar a liberdade e a independência não pode se concretizar na sua verdadeira existência humana uma vez que suas relações sociais, força de trabalho estão alienadas e fetichizadas pela mercadoria.

A compreensão da atual fase do capitalismo, ou seja, da globalização financeira pode também ser explicada, sem o erro de cometermos anacronismo, pelas importantes reflexões de Karl Marx sobre o capitalismo de sua época.

\section{Referências Bibliográficas}




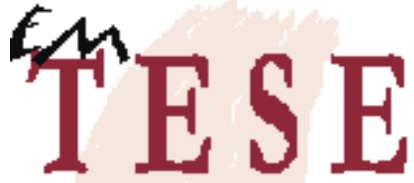

Revista Eletrônica dos Pós-Graduandos em Sociologia Política da UFSC

Vol. 6 - n. 3 janeiro-julho/2009

ISSN 1806-5023

ALEXANDER, Jeffrey. “A importância dos clássicos”. In: GIDDENS, A. e TURNER, J. (org.), Teoria social hoje. São. Paulo: Unesp, 1999.

BRAGA, José. Carlos, CINTRA, Marco Antonio. "Finanças dolarizadas e Capital Financeiro: exasperação sob comando americano.” IN: FIORI, J. L. (org.). O Poder Americano. Rio de Janeiro: Vozes, p. 253-308, 2004.

CHESNAIS, François. La finance mondialisée. Paris: Editions la découverte, 2004.

CINTRA, Marco Antonio, SCHERER, André. "Pensar o impensável: o desenrolar da crise de crédito global". Revista Princípios, abril/maio, 2008.

DUMÉNIL, Gérard. A América Latina na mundialização neoliberal. Retirado da internet: http://www.jourdan.ens.fr/levy/dge2005a.doc Acesso em 03/07/2008.

MARX, Karl; ENGELS, Fiedrich. A ideologia alemã. São Paulo: Martin Claret, 2006.

. Manuscritos Econômico-Filosóficos. São Paulo: Martin Claret, 2005.

. Os Manuscritos econômico-filosóficos: O terceiro manuscrito. Filosóficos e outros textos escolhidos. Os Pensadores. São Paulo: Abril Cultural, 1978.

O capital. livro 3.São Paulo: Nova Cultural, 1988.

ENGELS, Fiedrich. O manifesto do Partido Comunista. 11. ed. Petrópolis: Vozes, 2001.

MICHALET, Charles.-Albert. O que é a mundialização?. Edições Loyola, 2003. 


\section{留ESE}

Revista Eletrônica dos Pós-Graduandos em Sociologia Política da UFSC

Vol. 6 - n. 3 janeiro-julho/2009

ISSN 1806-5023

REICH, Robert. Supercapitalismo. Rio de Janeiro: Campus, 2008.

SINGER Paul. Economia: Da crise financeira à crise econômica. Retirado da internet: http:/www2.fpa.org.br/portal/modules/news/article.php?storyid=2485. Acesso em: 03/07/2008.

SCHERER, André. O modelo norte-americano de governança corporativa: gênese, instrumentos e conseqüências. Ensaios FEE, Porto Alegre, v. 24, n. 2, p. 429-452, 2003.

SKINNER, Quentin. "Meaning and understanding in the history of ideas". In: SKINNER, Q. Visions of Politics, Vol. 1 (Regarding Methods). Cambridge: Cambridge University Press, 2003. 